\title{
Magnesium levels in plasma and erythrocytes before and after histamine challenge
}

\author{
E. Zervas*, S. Loukides*, G. Papatheodorou**, K. Psathakis*, K. Tsindiris*, P. Panagou*, \\ N. Kalogeropoulos*
}

\begin{abstract}
Magnesium levels in plasma and erythrocytes before and after histamine challenge. E. Zervas, S. Loukides, G. Papatheodorou, K. Psathakis, K. Tsindiris, P. Panagou, N. Kalogeropoulos. C) ERS Journals Ltd 2000.

ABSTRACT: Previous studies have assessed the protective effect of nebulized magnesium sulphate on bronchial hyperreactivity. This study investigated the effect of histamine challenge on intracellular (erythrocytes) and extracellular (plasma) levels of magnesium and the possible relationship between degree of bronchial hyperreactivity and levels of $\mathrm{Mg}$ in plasma and erythrocytes.

The authors studied 42 mildly asthmatic patients (10 on inhaled steroids) and 20 healthy subjects. Histamine challenge was performed by the dosimeter method and provocative dose causing a $20 \%$ fall in forced expiratory volume in one second (PD20) (FEV1) was calculated. Mg levels were measured with a calmagite colourimetric assay, both at baseline and when FEV1 had fallen by $20 \%$.

The results showed that $\mathrm{Mg}$ levels in plasma did not significantly change after histamine challenge (from $2.06 \pm 0.02 \mathrm{mg} \cdot \mathrm{dL}^{-1}$ to $2.08 \pm 0.02 \mathrm{mg} \cdot \mathrm{dL}^{-1}$ respectively, $\mathrm{p}=\mathbf{0 . 1 4}$ ). Conversely there was a statistically significant decrease in $\mathrm{Mg}$ levels in erythrocytes between these two time points (from $1.84 \pm 0.02$ fmmol-cell to $1.78 \pm 0.02$ fmmol-cell $p<0.0001$ ). Similar results were observed when the subgroups were studied separately. There was no significant correlation between PD20, the difference in both magnesium concentrations (baseline-PD20 time) or the initial values of Mg levels in erythrocytes and plasma.

To conclude, histamine challenge reduces magnesium levels in erythrocytes while plasma levels remain unchanged. This histamine-induced decrease in magnesium levels occurs regardless of the diagnosis of asthma, and it is not correlated with the degree of bronchial hyperreactivity.
\end{abstract}

Eur Respir J 2000; 16: 621-625.

*Thoracic Medicine Dept. **CIinical Research Unit, Athens Army General Hospital, Athens, Greece.

Correspondence: S. Loukides

Smolika 2 Voula

16673 Athens

Greece

Fax: 003017494095

Keywords: Bronchial asthma bronchial hyperresponsiveness magnesium

Received: June 231999

Accepted after revision May 292000
Magnesium, the second most abundant intracellular cation (second only to potassium) [1], has shown to be an in vitro relaxant on bronchial smooth muscle [2]. The first description of the bronchodilator effect of $\mathrm{Mg}$ in acute asthma was carried out in 1936 by Rossello and PlA [3]. Previous studies have demonstrated the role of intravenous or nebulized magnesium sulphate $\left(\mathrm{MgSO}_{4}\right)$ as a helpful agent to reverse bronchospasm in acute asthma [4, 5].

Inhaled $\mathrm{Mg}$ attenuates methacholine and histamineinduced bronchoconstriction in patients with asthma in a dose-dependent way $[6,7]$. There is also some evidence that hypomagnesemia and low $\mathrm{Mg}$ intake are related to airway hyperresponsiveness, whereas dietary supplementation may result in improvement in asthmatic patients $[8$, 9]. These earlier observations lead to the plausible explanation that $\mathrm{Mg}$ levels may interfere with bronchial reactivity. However, the role of $\mathrm{Mg}$ in asthma is still controversial as other studies failed to demonstrate any benefit from inhaled or intravenous $\mathrm{Mg}$ in the treatment of acute and stable asthma $[10,11]$ or to correlate $\mathrm{Mg}$ levels to airway reactivity or protection against bronchoconstriction challenge $[12,13]$.
The aim of this study was to investigate the effect of bronchial challenge with histamine on intracellular (erythrocytes) and extracellular (plasma) levels of magnesium and examine the possible relationship between degree of bronchial hyperreactivity and levels of magnesium in plasma and erythrocytes.

Methods

Patients

Four different populations were tested: asthmatic patients (steroid treated or steroids-naive), healthy volunteers and a control group allowing the assessment of the analytical and biological variation of the magnesium assay Forty-two subjects (all male mean $\pm \mathrm{SD}$, forced expiratory volume in one second (FEV1) $93 \pm 1 \%$ of predicted (pred), mean age $22 \pm 0.4 \mathrm{yrs}$ ) were randomly selected from the outpatient clinic (Athens Army General Hospital). All were asthmatic according to the American Thoracic Society criteria [14]. Ten were receiving inhaled steroids and thirty two were steroid naive. Twenty healthy subjects, 
who were nonsmokers, with no history of atopy (negative skin prick tests to common allergens) were also included. All subjects were in a clinically stable condition with a baseline FEV 1 in excess of $80 \%$ of the predicted value and had not suffered from any respiratory tract infection for the last 6 weeks before the study. None of the subjects had risk factors for $\mathrm{Mg}$ depletion, received diuretics or any other $\mathrm{Mg}$-wasting drugs [1]. In order to assess the analytical and biological variation of the $\mathrm{Mg}$ assay, 20 of the randomly selected subjects characterized as control group (mean \pm SD age $22 \pm 0.8 \mathrm{yrs}, \mathrm{FEV} 191 \pm 2 \%$ of pred 6 asthmatics on inhaled steroids, 7 asthmatics steroid naive and 7 normal subjects), were asked to come on a different day, where $\mathrm{Mg}$ in erythrocytes and plasma were measured with a time difference of $15 \mathrm{~min}$ (the established average time for an histamine challenge procedure).

\section{Histamine challenge}

Bronchial hyperreactivity was measured by a rapid histamine inhalation test for the determination of PD20 [15]. Histamine $1 \%$ in $0.5 \%$ phenol (Hal, Lab BV, Ha arlem, the Netherlands) was inhaled in doubling doses starting from $100 \mu \mathrm{g}$ until FEV 1 had fallen $\geq 20 \%$ compared with FEV1 after an initial saline (0.9\%) inhalation. The bronchial aerosol provocation system (APS Jaeger, Würzburg, Germany) with the Sandoz nebulizer (Jaeger) was used in this procedure. The Sandoz nebulizer was calibrated to nebulize $5 \mu \mathrm{L}$ per nebulization and was triggered by inspiration on tidal ventilation. Each nebulization lasted for 0.5 seconds. Lung function was measured $1 \mathrm{~min}$ after each inhaled dose. PD20 was determined by linear interpolation on a semi-logarithmic scale. Normal reactions were considered those $>800 \mu \mathrm{g}$ for PD20. In all subjects, antihista-mines had been withdrawn for at least one week before the bronchial challenge. Asthmatic subjects stopped short or long-acting adrenergic bronchodilator for at least $12 \mathrm{~h}$ before the bronchial challenge.

\section{Magnesium concentration}

Venous blood samples were obtained without tourniquet from all the subjects in sitting position before and after bronchial challenge. In the control group, a time difference of $15 \mathrm{~min}$ was used. The aspirated blood was transferred to a metal free test tube containing sodium heparin and a complete blood count (CBC) was measured immediately. Plasma was separated from the erythrocytes within $30 \mathrm{~min}$ $(650 \times g$ for $10 \mathrm{~min})$. Of the isolated erythrocytes $100 \mu \mathrm{L}$ was aspirated and was lysed with $1.5 \mathrm{~mL}$ double distilled water. In the first 20 samples $\mathrm{Mg}$ in erythrocytes was determined both after washing (3 times with (caesium chloride) (CsCI) 145 mmol, pH: 7.40; osmolarity: 290$293 \mathrm{mOsm} / \mathrm{K} \mathrm{H}_{2} \mathrm{O}$ ) and without washing. No differences were detected (paired t-test $>0.5$ ) between the two methods. Thus, the remaining samples were analysed without washing. Samples of plasma with haemolysis or lipaemia were excluded from the study. The $\mathrm{Mg}$ concentration in plasma and in red blood cells was determined by a colourimetric assay using calmagite, a metallochromic dye [16]. In plasma the measurements were carried out without deproteinization and in red blood cells after deproteinization using sodium tungstate $\left(\mathrm{Na}_{2} \mathrm{WO}_{4}\right)$ at an acid $\mathrm{pH}$ (the lysed erythrocytes were reacted with $200 \mu \mathrm{L} 0.3 \mathrm{M} \mathrm{Na}_{2} \mathrm{WO}_{4}$ and $200 \mu \mathrm{L} 0.35 \mathrm{M}$ hydrogen sulphate $\left.\left(\mathrm{H}_{2} \mathrm{SO}_{4}\right)\right)$. Briefly $1 \mathrm{~mL}$ of working solution $\left(0.08 \mathrm{~g} \cdot \mathrm{L}^{-1}\right.$ calmagite, $0.04 \mathrm{~g} \cdot \mathrm{L}^{-1}$ ethyleneglycol-bis-( $\beta$-aminoethylether)- $\mathrm{N}^{\prime}, \mathrm{N}^{\prime}, \mathrm{N}^{\prime}, \mathrm{N}^{\prime}$-tetraacetic acid (EGTA), $0.28 \mathrm{Mm} \mathrm{KCN}, 0.34 \mathrm{M}$ potassium chloride (KCI), $0.98 \mathrm{~g} \cdot \mathrm{L}^{-1}$ Bion Ne-9 and $0.091 \mathrm{~g} \cdot \mathrm{L}^{-1}$ Bion PVP) was reacted with $20 \mu \mathrm{L}$ of the plasma or $200 \mu \mathrm{L}$ of the supernatant from the erythrocytes pellet deproteinization for $2 \mathrm{~min}$ at room temperature. The reaction product, a pink magnesium-calmagite complex, was quantitated at $532 \mathrm{~nm}$ using a double beam spectrophotometer (Unicon 940, Kontron Instruments, Tegimenta AG, Zurich, Switzerland). The investigator (GP) who performed the magnesium measurements was not aware of the clinical and functional status of the subjects.

\section{Lung function}

FEV1 was measured using a dry bellows spirometer (Vitalograph, 44000 series, Buckingham, UK). The best value of three measurements was expressed as a percentage of the predicted value.

\section{Statistics}

The study population was divided into four groups: (a) asthmatics steroid naive; (b) asthmatics on inhaled steroids; (c) healthy subjects; and finally (d) control group. The Mg levels in plasma and erythrocytes were equally compared not only in the whole study population, but also in each subgroup separately before and after bronchial challenge with histamine. In the control group the comparison was done between two measurements performed with a 15 min time difference. When the whole study population PD20 measurements were analysed they were not normally distributed, while $\mathrm{Mg}$ measurements showed a near normal distribution. Within each subgroup both $\mathrm{Mg}$ and PD20 measurements were normally distributed. Differences of $\mathrm{Mg}$ measurements within each subgroup were tested by a paired t-test, while differences between subgroups were tested with one way analysis of variance (ANOVA) with appropriated post hoc test (Bonferroni) for multiple group comparison. The relationship between PD20 and both magnesium concentrations (plasma and erythrocytes) were tested in the whole study population by Spearman's Rank test and in subgroups by the Pearson's test. Results are expressed as mean \pm SEM. A p-value of $<0.05$ was considered significant. The study was approved by the Hospital Ethics Committee.

\section{Results}

The general characteristics of all the subjects and of each subgroup separately, as well as baseline $\mathrm{Mg}$ levels in plasma and erythrocytes and PD20 are summarized in table 1. The initial Mg concentration in plasma and in erythrocytes did not differ significantly between normal subjects, asthmatics on inhaled steroids and those who were steroidnaive $(\mathrm{p}=0.9, \mathrm{p}=0.8$ respectively). There was no significant difference between $\mathrm{Mg}$ concentration in plasma 
Table 1. - Subjects general characteristics

\begin{tabular}{lccccc}
\hline & Age yrs & FEV1\% pred & Mg plasma mgr·dL & Mg erythrocytes fmmol·cell ${ }^{-1}$ & PD20 mg \\
\hline All subjects $\mathrm{n}=62$ & $22 \pm 0.4$ & $93.0 \pm 1.0$ & $2.06 \pm 0.02$ & $1.84 \pm 0.02$ & $0.56 \pm 0.05$ \\
Asthmatics steroid naive $\mathrm{n}=32$ & $21 \pm 0.4$ & $90.5 \pm 1.5$ & $2.06 \pm 0.03$ & $1.84 \pm 0.03$ & $0.23 \pm 0.02$ \\
Asthmatics on inhaled steroids $\mathrm{n}=10$ & $22 \pm 0.1$ & $94.0 \pm 3.5$ & $2.04 \pm 0.04$ & $1.86 \pm 0.06$ & $0.49 \pm 0.2$ \\
Normal subjects $\mathrm{n}=20$ & $23 \pm 0.8$ & $97.5 \pm 2.0$ & $2.10 \pm 0.03$ & $1.84 \pm 0.03$ & $1.20 \pm 0.30$ \\
Control group $\mathrm{n}=20$ & $22 \pm 0.8$ & $91.0 \pm 2.0$ & $2.07 \pm 0.02$ & $1.84 \pm 0 . .03$ &
\end{tabular}

Data are presented as mean \pm SD. FEV1: forced expiratory volume in one second; Mg: Magnesium; PD20: provocative dose causing a $20 \%$ fall.

before and after bronchial challenge with histamine (from $2.08 \pm 0.02 \mathrm{mg} \cdot \mathrm{dL}^{-1}$, to $\left.2.06 \pm 0.02 \mathrm{mg} \cdot \mathrm{dL}^{-1}, \mathrm{p}=0.14\right)$. In contrast, $\mathrm{Mg}$ concentration in erythrocytes decreased significantly compared to the baseline values (from $1.84 \pm 0.02$ fmol $\cdot$ cell $^{-1}$ to $1.78 \pm 0.02 \mathrm{fmol}^{\circ} \mathrm{cell}^{-1} \mathrm{p}=0.0001$ ) (fig. 1a). Similar results were observed when the 4 subgroups were studied separately (asthmatics: $1.84 \pm 0.03 \mathrm{fmol} \cdot \mathrm{cell}^{-1}{ }_{-}$ $1.78 \pm 0.03 \mathrm{fmol} \cdot \mathrm{cell}^{-1}, \mathrm{p}<0.0001$; asthmatics steroid naive: $-1.86 \pm 0.06 \mathrm{fmol} \cdot \mathrm{cell}^{-1}-1.81 \pm 0.06 \mathrm{fmol} \cdot \mathrm{cell}^{-1}, \mathrm{p}<0.001$, asthmatics on inhaled steroids: $1.84 \pm 0.03 \mathrm{fmol}^{-\mathrm{cell}^{-1}}{ }_{-}$ $1.77 \pm 0.03 \mathrm{fmol}^{\circ} \mathrm{cell}^{-1}, \mathrm{p}<0.0001$, in normal subjects) (fig. $1 b)$, except the control group in which no difference was observed for both $\mathrm{Mg}$ concentrations $\left(2.07 \pm 0.02 \mathrm{mg} \cdot \mathrm{dL}^{-1}-\right.$ $2.09 \pm 0.02 \mathrm{mg} \cdot \mathrm{dL}^{-1}, \mathrm{p}=0.18$ in plasma, $1.84 \pm 0.03 \mathrm{fmmol}$. cell $^{-1}-1.82 \pm 0.03 \mathrm{fmol} \cdot \mathrm{cell}^{-1} \mathrm{p}=0.16$ in erythrocytes) (fig. 1b).

There was no correlation between PD20 and the difference of both magnesium concentrations (baseline PD20 timepoint) or the initial values of magnesium levels in erythrocytes and plasma $(r=0.08 \mathrm{p}=0.5, \mathrm{r}=0.16, \mathrm{p}=0.7$ respectively).

\section{Discussion}

The authors have shown that bronchial challenge with histamine did not change $\mathrm{Mg}$ concentration in plasma, but caused a statistically significant decrease in intracellular $\mathrm{Mg}$ concentration. This fall was attributed to the histamineinduced bronchoconstriction, since $\mathrm{Mg}$ concentrations did not change significantly over a period of $15 \mathrm{~min}$ in the control group.

The usual method to determine $\mathrm{Mg}$ homeostasis is to measure Mg levels in the plasma. However, studies have shown the superiority of measuring the intracellular content of $\mathrm{Mg}$ in determining the $\mathrm{Mg}$ status of patients [1]. The preferred method for the determination of $\mathrm{Mg}$ in biological specimens is atomic absorption spectrophotometry. However, the instrumentation required is not generally available in clinical laboratories. Additionally, the calmagite colourimetric method (which was used in this study) is fairly accurate and precise and widely used in clinical laboratories [17], with a rather small negative proportional bias [18] and a good correlation $(\mathrm{r}=0.986)$ [19] compared to atomic absorption spectrophotometry.

$\mathrm{Mg}$ has long been thought to be a vital ion for maintaining the homeostasis of the bronchial smooth muscle. It is not known whether magnesium works via pharmalogical effects or repletion of body stores. Regarding pharmacological effects, several mechanisms have been proposed to explain the potential beneficial effect of magnesium in asthma. It has been shown to relax airway smooth muscle in vitro [2], probably by the modulation of calcium ion movement within the cell [20] and through transmembrane calcium channels [21, 22], as well as to broncho; dilate asthmatic airways in vivo [4, 5]. It has been demonstrated that histamine and methacholine PD20 threshold dose is moved to the right when the patients were pretreated with aerolized magnesium sulfate, with this effect considered to be similar than that observed with calcium channel blockers [6,7]. All of the above data supports the hypothesis that $\mathrm{Mg}$ may exert its effect on the final common path of bronchoconstriction by interfering with calcium handling on bronchial smooth muscle cells.
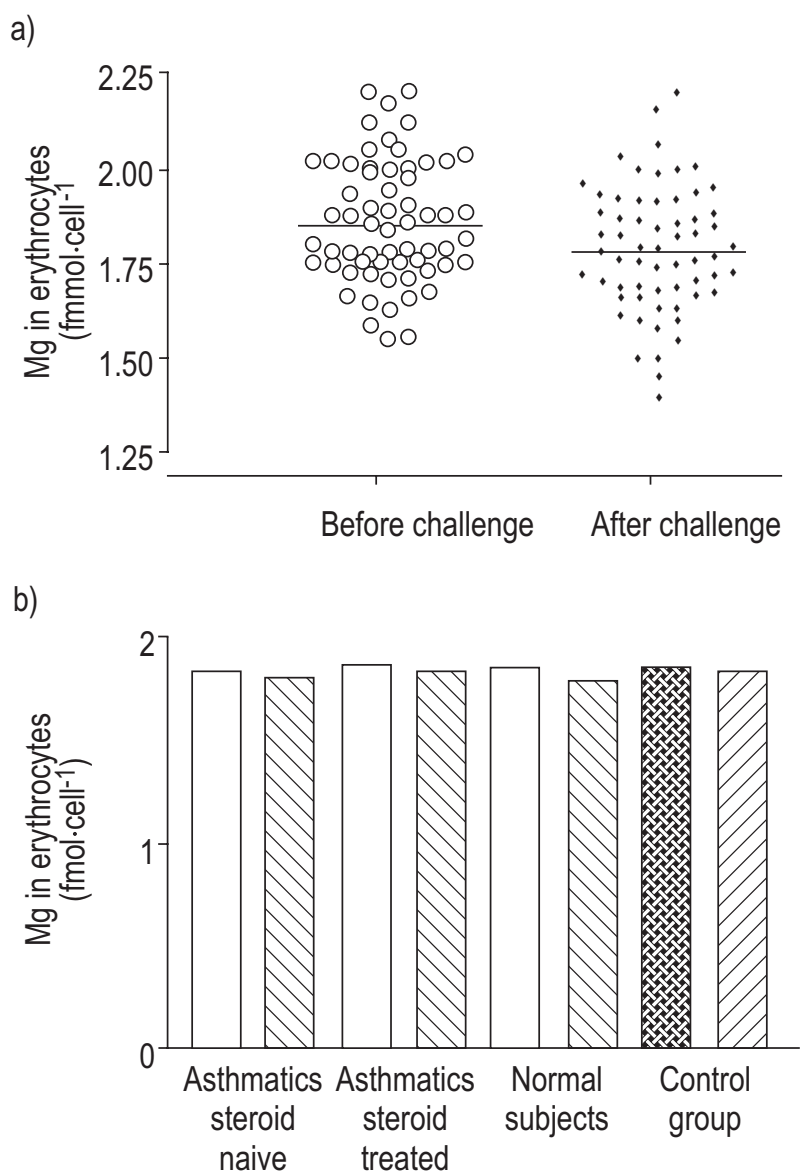

Fig. 1. - a) Magnesium concentration in erythrocytes before and after histamine challenge. $p<0.0001$. b) Magnesium concentration in erythrocytes before and after histamine challenge in the four study populations.

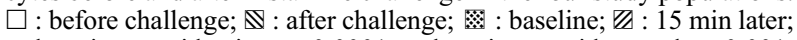
asthmatics steroid naive: $\mathrm{p}<0.0001$; asthmatics steroid treated: $\mathrm{p}<0.001$; normal subjects: $\mathrm{p}<0.0001$. 
The authors observed a significant decrease in the $\mathrm{Mg}$ concentration in erythrocytes after bronchial challenge with histamine in both asthmatics and healthy subjects, while at the same time plasma concentration remained stable. It is thus believed that the $\mathrm{Mg}$ ion moved from the intracellular space and was used as a natural calciumchannel blocker in order to relax airway smooth muscle and reverse bronchoconstriction. This hypothesis is partially supported by the protective role of magnesium in histamine induced bronchoconstriction [6], and by experimental data showing that $\mathrm{Mg}$ relaxes arterial smooth muscle, prestimulated with histamine by decreasing intracellular calcium [23].

The authors assume that when bronchoconstriction occurs during the histamine challenge test, free radicals such as hydrogen peroxide can be released through direct action of histamine in enzymatic reactions [24] and inflammatory cells [25] or indirect action via activation of Cfibres and tachycinins [26]. The hydrogen peroxide can act as an indirect trigger to the erythrocytes (destroying the $\mathrm{Na}^{+} / \mathrm{Mg}^{2+}$ ATPase antiport) to poor out magnesium [27]. Inflammatory chemokines as interleukins might take part in this process but they cannot explain the fall of $\mathrm{Mg}$ in the erythrocytes of normal subjects. This significant fall of $\mathrm{Mg}$ concentration in erythrocytes seems to be irrespective of bronchial hyperresponsiveness severity as is shown by the lack of correlation between PD20 to histamine and the percentage (\%) fall of $\mathrm{Mg}$ concentration in erythrocytes. This confirms the main hypothesis that $\mathrm{Mg}$ ions move out from the intracellular space when bronchoconstriction occurs, independently of the dose of histamine (degree of bronchial hyperreactivity) required for this effect. The results of the control group also confirm that the observed fall of erythrocytes $\mathrm{Mg}$ after histamine challenge is due to challenge itself and not because of the biological and analytical variation of magnesium concentration in erythrocytes. This is in agreement with previous observations which showed good reproducibility of erythrocytes $\mathrm{Mg}$ measurements within the day (coefficient of variation $(\mathrm{CV})=4 \%$ ) [28].

In this study it was been shown that the concentrations of $\mathrm{Mg}$ in plasma and erythrocytes of asthmatic patients are within normal rates and did not differ significantly from those found in healthy subjects. This is in agreement with previous reports $[12,29,30]$, but in contrast to two recent reports $[31,32]$ which demonstrated low magnesium concentrations in the erythrocytes of asthmatic patients. These controversial results can be attributed to the differences in magnesium intake between different countries. The "Greek diet" is rich in products with a high magnesium content (unprocessed cereals, vegetables and legumes) [1] leading to a rather small possibility of hypomagnesemia in the majority of the population. Another possible explanation for the above difference is that their studies included subjects with dissimilar age ranges compared to this study (only young males) which probably makes them incomparable, since intracellular magnesium varies substantially with age [33]. Another finding which was not confirmed by this study was the correlation between bronchial hyperreactivity and the initial values of $\mathrm{Mg}$ concentration in erythrocytes. Since the authors did not observe any difference in intracellular $\mathrm{Mg}$ concentration between asthmatic and healthy subjects it is reason- able not to expect any correlation between bronchial hyperreactivity and $\mathrm{Mg}$ concentration in erythrocytes.

To conclude, this study shows that bronchial challenge with histamine caused a statistically significant fall in intracellular (erythrocytes) Mg with no effect in plasma concentration of this ion. This fall did not correlate with the degree of bronchial hyperreactivity to histamine. Further studies are needed to determine the role of intra- and extracellular concentrations of $\mathrm{Mg}$ in exacerbated asthma.

\section{References}

1. Reinhart R. Magnesium metabolism. Arch Intern Med 1988; 148: 2415-2420.

2. Spivey WH, Skobelolf EM, Levin RM. Effect of magnesium chloride on rubbit bronchial smooth muscle. Ann Emerg Med 1990; 19: 1017-1012.

3. Rosello HJ, Pla JC. Sulfato de magnesio en la crisis de asma. Prensa Med Argontina 1936; 29: 1677-168.

4. Bloch H, Silverman R, Mancherje N, Grant S, Jagninas L, Scharf S. Intravenous magnesium sulfate as an adjunct in the treatment of acute asthma. Chest 1995; 107: 15761581.

5. Mangat HS, D'Souza G.A, Jacob MS. Nebulized magnesium sulfate versus nebulized salbutamol in acute bronchial asthma: a clinical trial. Eur Respir J 1998; 12: 341344.

6. Rolla G, Bucca C, Bugiuni M, Arossa W, Spinacis S. Reduction of histamine-induced bronchoconstriction by magnesium in asthmatic subjects. Allergy 1987; 42: 186188.

7. Rolla G, Bucca C, Arrossa W, Bugiani M. Magnesium attenuates methacholine induced bronchoconstriction in asthmatics. Magnesium 1987; 6: 201-204.

8. Britton D, Pavard I, Chards K, et al. Dietary magnesium, lung function, wheezing and airway hyperactivity in a random adult population sample. Lancet 1994; 344: 357362.

9. Hil J, Micklewright A, Lewis S, Britton J. Investigation of the effect of short-term change in dietary magnesium intake in asthma. Eur Respir J 1997; 115: 937-943.

10. Tiffany BR, Berk WA, Todd IK, White SR. Magnesium bolus or infusion fails to improve expiratory flow in acute asthma exacerbation. Arch Intern Med 1995; 155: 271276.

11. Chande VT, Skoner DP. A trial of nebulized magnesium sulfate to reverse bronchospasm in asthmatic patients. Ann Emerg Med 1992; 21: 1111-1115.

12. Hill JM, Britton J. Effects of intravenous magnesium sulfate on airway calibre and airway reactivity to histamine in asthmatic subjects. Br J Clin Pharmacol 1996; 42: 629-631.

13. Hill J, Lewis S, Britton J. Studies of the effect of inhaled magnesium on airway reactivity to histamine and adenosine monophosphate in asthmatic subjects. Clin Exp Allergy 1997; 27: 546-551.

14. American Thoracic Society. Standards for the diagnosis and care of patients with chronic obstructive pulmonary disease (COPD) and asthma. Am Rev Respir Dis 1987; 136: 225-244.

15. Sovijarvi AR, Malberg LP, Reinikminen K, Ryhila Poggins H. A rapid dosimetric method with controlled tidal breathing for histamine challenge. Chest 1993; 104: 164-170.

16. Giluder EM, Heth DA. Calorimetric determination with 
bound "calmagite" of magnesium in human blood plasma. Clin Chem 1971; 17: 663-666.

17. Jacob RA. Trace Elements. In: Tietz NW, ed. Fundamentals of Clinical Chemistry. 3rd edn. Philadelphia, W.B. Saunders Co, 1987; pp. 521-524.

18. Khayam-Bashi K, Liu TZ, Walter V. Measurements of serum magnesium with a centrifugal analyser. Clin Chem 1977; 23: 289-291.

19. Liodtke RJ, Kroon G. Automated calmagite compleximetric measurement of magnesium in serum with sequential addition of EDTA to eliminate endogenous interference. Clin Chem 1984; 26: 1801-1804.

20. Bois P. Effect of magnesium deficiency on mast cells and a urinary histamine in rats. Br J Exp Path 1963; 44: 151155.

21. Kass RS, Lederez WJ, Tsin RW, et al. Role of calcium ions in transient inward currents and after contractions induced of stophandthidin in cardiac Purkinjee fibers. $J$ Physiol 1978; 281: 187-208.

22. Dunnet J, Naylon T. Calcium efflux from cardiac sarcoplasmatic reticulum: effects of calcium and magnesium. $J$ Mol Cell Cardiac 1978; 10: 487-449.

23. Elizabeth K, Gilbert DA, Singer HA, Rembold CM. Magnesium relaxes arterial smooth muscle by decreasing intracellular $\mathrm{Ca}^{2+}$ without changing intracellular $\mathrm{Mg}^{2+} . J$ Clin Invest 1992; 89: 1988-1994.

24. Hasebe Y, Toda S, Aoki K, Tonabe H, Uchigama S. Specific and amplified current responses to histidine and histamine using immobilized coppermonoamine oxidase membrane electrode, based on novel ascorbate oxidase activity induced by exogenous ligands. Annal Biochem 1997; 251 (1): 32-38.
25. Barnes J. Reactive oxygen species and airway inflammation. Free Rad Biol \& Med 1990; 9: 235-243.

26. Lai YL, Fung ZX, Zhang HG. Noncholinergic airway constriction: role of axon reflex and oxygen radicals. Clin J Physiol 1993; 36: 133-140.

27. Gunther T, Vormann G, Forster RM. Effect of oxygen free radicals on $\mathrm{Mg}^{2+}$ efflux from erythrocytes. Eur J Clin Chem Clin Biochem 1994; 32: 4273-4277.

28. Huijgen H, Van Ingen H, Sanders R, Gaffar F, Oosting J, Sanders G. Precision of the magnesium determination in the mononuclear blood cells and erythrocytes. Clin Biochem 1997; 30: 203-208.

29. De Valk HM, Kok PTM, Sruyvenberg A, et al. Extracellular and intracellular magnesium concentrations in asthmatics patients. Eur Respir J 1993; 6: 1122-1125.

30. Fantidis P, Ruiz Cucho J, Morin M, Madero JR, Solera J, Herrero E. Intracellular (polymorphonuclear) magnesium content in patients with bronchial asthma between attacks. $J$ R Soc Med 1995; 88: 441-445.

31. Dominquez LJ, Barbagallo $\mathrm{M}$, Di Lorenzo $\mathrm{G}$, et al. Bronchial reactivity and intracellular magnesium: a possible mechanism for the bronchodilating effects of magnesium in asthma. Clin Sci (Colch) 1998; 95: 137-142.

32. Emelyanov A, Fedoseev G, Barnes PJ. Reduced intracellular magnesium concentrations in asthmatic patients. Eur Respir J 1999; 13: 38-40.

33. Barbagallo M, Dominquez LJ, Putignano E, BarbagalloSangiorgi G, Resnick LM. Effect of aging on intracellular divalent cation metabolism: a link to the increased incidence of hypertension and non-insulin dependent diabetes mellitus in the elderly? Arch Gerontol Geriatr 1996; 5: 233-238. 